\title{
Risk Measurement and Performance Evaluation of Equity Funds Based on ARMA-GARCH Family Model
}

\author{
Jingling Yang, Guoqiang Tang*, Duancui Yang\#, Jianwen Zhang \\ College of Science, GuiLin University of Technology, GuiLin, China \\ Email:1587747575@qq.com, ${ }^{*}$ tanggq@glut.edu.cn, ${ }^{*}$ yangdc@glut.edu.cn,873062165@qq.com
}

How to cite this paper: Yang, J.L., Tang, G.Q., Yang, D.C. and Zhang, J.W. (2020) Risk Measurement and Performance Evaluation of Equity Funds Based on ARMA-GARCH Family Model. Open Journal of Statistics, 10, 325-340.

https://doi.org/10.4236/ojs.2020.102022

Received: March 6, 2020

Accepted: April 26, 2020

Published: April 29, 2020

Copyright $\odot 2020$ by author(s) and Scientific Research Publishing Inc. This work is licensed under the Creative Commons Attribution International License (CC BY 4.0).

http://creativecommons.org/licenses/by/4.0/

\section{(c) (i) Open Access}

\begin{abstract}
There are few comprehensive studies on risk measurement and performance evaluation of stock funds in China. This paper uses the ARMA-GARCH family model to analyze the volatility characteristics of equity funds under the $\mathrm{t}$-distribution and Generalized error distribution (GED), and combines CVaR, PM (Second revised sharp ratio) and CVaR-RAROC (Revised RAROC) to comprehensively evaluate equity funds risk and performance. The empirical analysis of five equity funds in China from October 28, 2010 to May 17, 2019 shows that: Comprehensive evaluation of the risk and performance of equity funds can comprehensively and effectively examine the risks and returns of equity funds, helping investors, financial institutions and regulatory agencies to more fully understand the risks and performance of equity funds.
\end{abstract}

\section{Keywords}

Equity Funds, ARMA-GARCH Family, PM, CVaR-RAROC

\section{Introduction}

Securities investment fund is a kind of collective investment tool which gathers small-scale funds and uses a variety of investment methods to carry out professional operation. It has been favored by investors since its birth and plays an important role in economic development. Equity funds are a kind of open-end fund. It is an investment fund with stocks as its investment object. The main functions of equity funds are to concentrate the small amount of investment of public investors into large-scale funds and invest in different stock combinations. Equity funds are the main institutional investor in the stock market. There are risks associated with investment returns. Equity funds have the greatest fluctua${ }^{*, \#}$ Corresponding authors. 
tions in risk and return among all fund types. Studying its risks and performance is of great significance to investors, financial institutions and regulators.

At present, there have been many studies on the GARCH family model and the risk and performance measurement of China's open-end fund. Song Guanghui et al. [1] used the VaR and CVaR of GARCH family model to study the risk of Shibor. The research shows that the GED is better than the normal distribution and t-distribution, and the t-distribution hypothesis is not suitable to describe the dynamic characteristics of the logarithm yield of Shibor's weekly interest rate; CVaR model can effectively make up for the deficiency of VAR model and effectively measure the risk of actual loss. Wei Zhengyuan et al. [2] established a new realized GARCH-GED model. The empirical research results show that compared with the realized GARCH model under the assumption of normal distribution, the realized GARCH-GED model can better describe the leverage effect of volatility and improve the precision of tail risk to some extent. Zhao Zhenquan and Li Xiaozhou [3] use GARCH model to study the volatility of open-end fund' return rate, and use absolute VaR and RAROC index to comprehensively study the risk and return of open-end fund. Huang Chongzhen and Cao Qi [4] used the China Asset Shanghai-Shenzhen 300 ETF connection as an example to use the GARCH family model to study the risk of open-end funds. The research shows that the GARCH-M model under the t-distribution can better measure risk. Qi Yue and Sun Xinming [5] applied the method of copying the investment strategy of the fund for the first time to create a new investment portfolio and calculate its investment income. As a benchmark for fund performance evaluation, dynamically evaluate the fund's investment performance and investment behavior. Liu Junshan [6] pointed out that CVaR is better than VaR in nature, and proved that the CVaR index is consistent with the stochastic dominance theory. Zhu Fuyun, Zhou Ying, and Chen Yuan [7] The VaR method based on the EGARCH-GED model effectively characterizes the market risk of securities investment fund. Sharpe ratio and RAROC (risk-adjusted capital return) effectively evaluate the performance of securities investment fund. Tang Zhenpeng and Peng Wei [8] introduced CVaR into the RAROC model, which more accurately measures risk, improves accuracy, and provides a good performance reference index for fund investors. Huang Jinbo, Li Zhongfei, and Ding Jie [9] introduced CVaR into the Sharpe ratio model. This indicator overcomes the shortcomings of traditional Sharpe ratios that do not meet the monotonicity of stochastic dominance and does not consider high-order moment information. It can more accurately characterize risk-adjusted Return on assets.

Previous studies have shown that: 1) $\mathrm{CVaR}$ is more reasonable in measuring risk than VaR; 2) PM and CVaR-RAROC are more effective in measuring the performance of financial products; 3 ) The effects of t-distribution and GED are more effective than those of the normal distribution model. At present, there are few comprehensive studies on the risk measurement and performance evaluation of equity funds. This paper uses the ARMA-GARCH family model to analyze the volatility characteristics of equity funds under the conditions of t-distribution 
and GED. Combined with CVaR, PM and CVaR-RAROC, the risk and performance of equity funds are comprehensively evaluated. The studies show that the comprehensive evaluation of the risk and performance of the equity funds can help investors, financial institutions and regulators to understand the risk and performance of the equity funds more comprehensively and effectively.

\section{Theoretical Model}

\subsection{ARMA and GARCH Family Models}

$\mathrm{ARCH}$ model is widely used to study the characteristics of financial asset return, such as peak and thick tail, volatility aggregation, asymmetry and so on. In real economic phenomena, high-order ARCH effects and lagging conditional variance often exist in economic time series, which increases the adaptiveness of conditional variance. At this time, the GARCH model is introduced to represent higher-order ARCH models. This paper establishes dynamic conditional mean equations and conditional Heteroskedasticity equations to study the volatility characteristics of equity funds. In the GARCH family model, the residual distributions are: normal distribution, t-distribution, and GED. The research in this paper mainly studies the volatility characteristics and risk performance of equity funds in the context of t-distribution and GED.

\subsubsection{ARMA Model}

In the 1970s, American statistician Box GEP and British statistician Jenkins GM [10] proposed an autoregressive moving average model (ARMA model). The general ARMA model expression is:

$$
\mu_{t}=\phi_{0}+\phi_{1} \mu_{t-1}+\cdots+\phi_{p} \mu_{t-p}+\varepsilon_{t}-\theta_{1} \varepsilon_{t-1}-\cdots-\theta_{q} \varepsilon_{t-q}
$$

in which, $\left\{\varepsilon_{t}\right\}$ is a random sequence, $\mu_{t}$ is the value of the current period. $p$ and $q$ are the lag orders of the autoregressive term (AR) and moving average term (MA), respectively.

\subsection{2. $\operatorname{GARCH}(p, q)$ Model}

GARCH $(p, q)$ was proposed by Bollerslov [11] in 1985, and the expression is:

$$
\sigma_{t}^{2}=\omega+\sum_{i=1}^{p} \alpha_{i} \mu_{t-i}^{2}+\sum_{j=1}^{q} \beta_{j} \sigma_{t-j}^{2}
$$

in which, $\omega$ is a constant term, $p$ and $q$ are the maximum lag order of GARCH term and ARCH term; $\mu_{t}$ is a residual term, and $\sigma_{t}$ is a conditional standard deviation of $\mu_{t}$.

\subsubsection{GARCH-M Model}

In 1987, Engle, Lilien, and Robbins [12] proposed the GARCH-M model, which added a volatility term to the response regression or mean equation. The GARCH-M model was applied to the financial field where expected returns and expected risks are closely related. Use this model to describe the change in risk premium over time. 
The expression of the GARCH-M model is:

$$
\left\{\begin{array}{l}
y_{t}=\delta_{0} x_{t}+\delta_{1} f\left(\sigma_{t}^{2}\right)+\mu_{t} \\
\sigma_{t}^{2}=\omega+\sum_{i=1}^{p} \alpha_{i} \mu_{t-i}^{2}+\sum_{j=1}^{q} \beta_{j} \sigma_{t-j}^{2}
\end{array}\right.
$$

in which, $x_{t}$ is a stationary random variable, $f\left(\sigma_{t}^{2}\right)$ is a function of conditional variance $\sigma_{t}^{2}, \delta_{1}$ is a risk premium coefficient, and $C$ represents the effect of the predicted risk fluctuation on $y_{t}$ can be observed. When $\delta_{1}>0$, risk compensation $\gamma_{1} f\left(\sigma_{t}^{2}\right)>0$, high return means high risk.

\subsubsection{TGARCH Model}

The threshold GARCH model (TGARCH model) was proposed by Zakoian [13] and Glosten et al. [14] respectively, and its expression is:

$$
\left\{\begin{array}{l}
\sigma_{t}^{2}=\omega+\sum_{i=1}^{p} \alpha_{i} \mu_{t-1}^{2}+\sum_{j=1}^{q} \beta_{j} \sigma_{t-1}^{2}+\gamma \mu_{t-1}^{2} d_{t-1} \\
d_{t}= \begin{cases}0, & \mu_{t} \geq 0 \\
1, & \mu_{t}<0\end{cases}
\end{array}\right.
$$

$\mu_{t} \geq 0$ means good news and $\mu_{t}<0$ means bad news. $\gamma \mu_{t-1}^{2} d_{t-1}$ is an asymmetric term, indicating that the influence of positive news and negative news on conditional variance is asymmetric. If $\gamma \neq 0$, it means that the impact of the shock response is asymmetric; if $\gamma>0$, Increase the leverage effect, and the shock will increase the fluctuation, and vice versa.

\subsubsection{EGARCH Family Model}

In 1991, Nelson [15] proposed an EGARCH model with guaranteed positive variance. Its expression is:

$$
\log \left(\sigma_{t}^{2}\right)=\omega+\sum_{i=1}^{q} a_{i}\left|\frac{\mu_{t-i}}{\sigma_{t-i}}-E\left(\frac{\mu_{t-i}}{\sigma_{t-i}}\right)\right|+\sum_{j=1}^{p} \beta_{j} \log \left(\sigma_{t-j}^{2}\right)+\sum_{k=1}^{\gamma} \gamma_{k} \frac{\mu_{t-k}}{\sigma_{t-k}}
$$

in which, $\sigma_{t}^{2}$ in logarithmic form guarantees that the value of $\sigma_{t}^{2}$ is non-negative, and does not require that the coefficients on the right side of the equation be non-negative. The solution process is simpler. If $\gamma_{k} \neq 0$, the impact of information is asymmetric; if $\gamma_{k}>0$, the impact of good news is greater than the impact of negative news, and vice versa.

\subsection{Concepts and Calculations of VaR and CVaR}

\subsubsection{The Concept of VaR and CVaR}

The VaR method (Value at Risk, referred to as VaR), known as the value-at-risk model, is often used in the risk management of financial institutions. It was proposed in 1993. The VaR model has been widely adopted by many financial institutions and has become the mainstream method for financial market risk measurement.

However, many empirical studies show that VaR method has its own insurmountable defects. Rockafeller and Uryasev [16] proposed Conditional Value at 
Risk (CVaR) in 2000. CVaR refers to the average value of portfolio losses when the portfolio losses are greater than a given $\mathrm{VaR}$ value. $\mathrm{CVaR}$ can replace $\mathrm{VaR}$ as a financial risk management tool. CVaR satisfies subadditiveness, positive homogeneity, monotonicity, and transfer invariance, which overcomes the shortcomings of VaR.

\subsubsection{Calculation of VaR and CVaR}

The calculation formula of $\mathrm{VaR}$ is expressed as:

$$
\mathrm{VaR}=P_{t-1} Z_{\alpha} \sigma_{t}
$$

in which, $P_{t-1}$ is the value of the asset on day $t-1, Z_{\alpha}$ is the quantile of $\alpha$ at a given confidence level, and $\sigma_{t}$ is the standard deviation of conditions.

According to the definition, the CVaR expression based on the GARCH family model is:

$$
\mathrm{CVaR}=\frac{P_{t-1} \sigma_{t}}{1-c} \int_{-\infty}^{-Z} f(q) q \mathrm{~d} q
$$

$c$ is the given significance level. Function $f(q)$ is the probability density of the yield series. In the case of a normal distribution, the specific calculation of CVaR is:

$$
\mathrm{CVaR}=-\frac{P_{t-1} \sigma_{t}}{(1-c) \sqrt{2 \pi}} \mathrm{e}^{\frac{-z^{2}}{2}}
$$

Under $\mathrm{t}$-distribution, the specific calculation of $\mathrm{CVaR}$ is:

$$
\mathrm{CVaR}=\frac{P_{t-1} \sigma_{t}}{1-c} \frac{\sqrt{d} \Gamma((d+1) / 2)}{(d-1) \sqrt{\pi} \Gamma(d / 2)}\left(1+\frac{Z^{2}}{d}\right)^{-\frac{d-1}{2}}
$$

in which, $\Gamma$ is the gamma function. $d$ is the degree of freedom.

Under the GED, the specific calculation of CVaR is:

$$
\mathrm{CVaR}=-\frac{P_{t-1} \sigma_{t}}{1-c} \int_{-\infty}^{-Z} q \frac{q \exp \left(-\frac{1}{2}\left|\frac{q}{\lambda}\right|^{d}\right)}{\lambda \Gamma\left(\frac{1}{d}\right) 2^{\frac{d+1}{d}}}
$$

in which, $\lambda=\left[\frac{2^{(-2 / d)} \Gamma(1 / d)}{\Gamma(3 / d)}\right]^{1 / 2}$.

After the value of CVaR is obtained, it is tested for validity, and the DLC is used to measure the actual loss over VaR. The definition of the statistic is:

$$
\mathrm{DLC}=\left|\frac{1}{N} \sum_{i+1}^{N} X_{i}-\frac{1}{N} \sum_{i+1}^{N} \mathrm{CVaR}_{i}\right|
$$

in which, $X_{i}$ is the actual loss that exceeds VaR, DLC is the absolute value of the difference between the expected value of actual loss and the expected value of CVaR., $N$ is the number of days of actual failure. The smaller the DLC, the closer the expected value of actual loss and the expected value of $\mathrm{CVaR}$ are, the $\mathrm{CVaR}$ measure the higher the accuracy, and vice versa. 


\subsection{Performance Evaluation Index}

\subsubsection{Concepts and Calculations of SHARPE Ratio, Revised Sharpe Ratio, PM}

The Sharpe Ratio, also known as the Sharpe Index, is one of three classic indicators that consider both returns and risks. The Sharpe ratio uses standard deviation to measure the risk of the returns of currency funds. The Sharpe ratio can be used as an important basis for fund performance evaluation only when considering the purchase of a certain fund among many funds. Therefore, the Sharpe ratio can be used as a standard for fund performance evaluation index. The calculation formula is:

$$
\mathrm{sp}=\frac{\overline{R_{p}}-\overline{R_{f}}}{\sigma_{p}}
$$

in which, sp is the sharp value of the equity funds, $\overline{R_{P}}$ is the average return rate of the equity funds, and $\overline{R_{f}}$ is the risk-free interest rate. Under the current conditions of China's stock market, there is actually no uniform standard for the selection of the risk-free rate of return. Internationally, short-term government bond yields are generally used as market risk-free returns. Therefore, this paper uses the one-year Treasury bond rate $(3.6661 \%)$ as the risk-free rate. $\sigma_{p}$ is the standard deviation of the return on equity funds. The larger the Sharpe ratio, the greater the return than the risk, the better the fund's performance.

There are certain limitations to using standard deviation as a risk indicator. Revising the Sharpe Index solves this limitation and introduces VaR instead of standard deviation. Its expression is:

$$
\mathrm{VaR}-\mathrm{sp}=\frac{\overline{R_{p}}-\overline{R_{f}}}{\mathrm{VaR}}
$$

$\mathrm{VaR}$ is the value-in-risk calculated based on the GARCH family model.

PM is the second revision of the Sharp Index, which is the introduction of CVaR instead of VaR by Golden Wave et al. [6].

$$
\mathrm{PM}=\frac{\overline{R_{p}}-\overline{R_{f}}}{\mathrm{CVaR}}
$$

\subsubsection{Concepts and Calculations of RAROC and CVaR-RAROC}

RAROC (Risk Adjusted Return on Capital) is a risk-adjusted return on capital. It is a financial product indicator proposed by Banker Trust in the 1970s. It is the ratio of the rate of return on assets and the amount of value at risk during the sample period. Both benefits and risks are considered. Its expression is:

$$
\mathrm{RAROC}=\frac{\mathrm{ROC}}{\mathrm{VaR}}
$$

in which, ROC is the expectation of return on assets. The larger the RAROC, the larger the ratio of benefits to risks, and the better the performance. 
$\mathrm{CVaR}$ makes up for the shortcomings of $\mathrm{VaR}$ in measuring risk and has a better measurement effect. Tang Zhenpeng et al. [9] used CVaR instead of VaR to calculate risk-adjusted capital gains. The expression is:

$$
\mathrm{CVaR}-\mathrm{RAROC}=\frac{\mathrm{ROC}}{\mathrm{CVaR}}
$$

\section{Empirical Analysis}

\subsection{Selection and Processing of Sample Data}

This paper selects the daily unit net value of five equity funds, namely Everbright Quantitative Stock (360001), E Fund Consumption Industry (110022), Yinhua Shenzhen Securities 100 graded (161812), Yinhua-Dow Jones 88 Index A (180003), China Merchants Shenzhen Stock Exchange 100 Index A (217016), as the research object. The ARMA-GARCH family model is used to analyze the volatility characteristics of equity funds under t-distribution and GED. Combine CVaR, PM and CVaR-RAROC to comprehensively evaluate the risk and performance of equity funds. The data of this paper is from fund.eastmoney.com. The time span of the sample is from October 28, 2010 to May 17, 2019, with a total of $2090 \mathrm{ob-}$ servations. Convert the data to the rate of return and obtain 2089 observations. The calculation formula is as follows:

$$
R_{t}=\ln P_{t}-\ln P_{t-1}
$$

in which, $R_{t}$ is the daily rate of return of the equity funds, $P_{t}$ and $P_{t-1}$ are the unit net values of the day $t$ and day $t-1$, respectively. The data analysis of this paper is realized by R 3.5.1, Eviews 9 and MATLAB 2015b.

\subsection{Basic Description Analysis}

The calculation formulas of standard deviation, skewness and kurtosis are as follows:

$$
\begin{gathered}
s t d=\sqrt{\frac{1}{N} \sum_{i=1}^{N}\left(R_{t}-\bar{R}_{t}\right)^{2}} \\
s k=\frac{\sum_{i=1}^{N}\left(R_{t}-\bar{R}_{t}\right)^{3}}{(N-1) s t d^{3}} \\
k t=\frac{\sum_{i=1}^{N}\left(R_{t}-\bar{R}_{t}\right)^{4}}{(N-1) s t d^{4}}
\end{gathered}
$$

in which, std is the standard deviation, sk is the skewness, and $k t$ is the kurtosis, $\bar{R}_{t}$ is the average rate of return.

The basic statistics of the daily rate of return of the sample are shown in Table 1 below. 
From Table 1, it is known that the average daily rates of return of all samples are around 0 . The highest average daily rate of return is in the E Fund consumer industry (110022), and the lowest is Yinhua Shenzhen Securities 100 graded (161812). The standard deviations are all close to 0 . The largest standard deviation is China Merchants Shenzhen Stock Exchange 100 Index A (217016) and the smallest is Yinhua-Dow Jones 88 Index A (180003). The skewness of the samples are all negative. In addition, the kurtosis of the rate of return of the samples are all greater than 3, indicating that the samples are all fat tail distribution. In addition, the Jarque-Bera are all above 1000, and the adjoint probabilities are all close to 0 . Therefore, the sample's rate of return has a phenomenon of peaks and fat tails, and the samples do not obey the normal distribution.

An non stationary series does not have convergence. If the time series is not stable, applying it to the model will reduce the reliability of the model. This paper uses ADF statistics to test the stationarity of the rate of return. As shown in Table 2 .

From Table 2, it is known that the ADF values are $-43.27519,-34.73255$, $-44.00777,-34.41966$, and -43.82818 , which are far less than the $1 \%$ critical value, $5 \%$ critical value, and $10 \%$ critical value, and the Prob are all 0 , so the original is rejected. Then it is determined that the rate of return of samples is a stationarity series, and the model has credibility.

Table 1. Basic statistics.

\begin{tabular}{cccccc}
\hline Statistics & 360001 & 110022 & 161812 & 180003 & 217016 \\
Mean & 0.0000 & 0.0005 & -0.0002 & 0.00003 & 0.0000 \\
median & 0.0005 & 0.0007 & 0.0000 & 0.0000 & 0.0000 \\
Maximum & 0.0623 & 0.0783 & 0.0705 & 0.0606 & 0.0718 \\
Minimum & -0.0824 & -0.0816 & -0.1148 & -0.0803 & -0.0928 \\
Std.Dev & 0.0150 & 0.0146 & 0.0160 & 0.0136 & 0.0162 \\
Skewness & -0.8237 & -0.4182 & -0.8329 & -0.4805 & -0.7410 \\
Kurtosis & 7.4274 & 6.7209 & 7.9679 & 7.6036 & 7.6273 \\
Jarque-Bera & 1942.390 & 1265.384 & 2389.714 & 1925.042 & 2054.928 \\
\hline
\end{tabular}

Table 2. Stationarity test.

\begin{tabular}{ccccccc}
\hline Sample & ADF statistic & $1 \%$ level & $5 \%$ level & $10 \%$ level & Prob & Stationarity \\
\hline 360001 & -43.27519 & -3.433284 & -2.862722 & -2.567445 & 0.0000 & stable \\
110022 & -34.73255 & -3.433284 & -2.862722 & -2.567445 & 0.0000 & stable \\
161812 & -44.00777 & -3.433284 & -2.862722 & -2.567445 & 0.0001 & stable \\
180003 & -34.41966 & -3.433284 & -2.862722 & -2.567445 & 0.0000 & stable \\
217016 & -43.82818 & -3.433284 & -2.862722 & -2.567445 & 0.0001 & stable \\
\hline
\end{tabular}


The autocorrelation of 5 samples was tested, and the autocorrelation coefficient AC and partial autocorrelation coefficient PAC were calculated. Both the methodology employed by EVIEWS or R results considered that 5 samples had autocorrelation.

\subsection{Heteroskedasticity Test}

The timing diagram of each sample is shown in Figure 1 below.

In which, the horizontal axis is the time axis, and the vertical axis is the rate of return. As can be seen from Figure 1, the rate of return of the samples exhibited significant fluctuation aggregation during the samples period. In which, Everbright Quantitative Stock (360001) has the largest fluctuation range, while E Fund Consumption Industry (110022) and Yinhua Shenzhen Securities 100 graded (161812) have relatively small fluctuation ranges.

According to the AIC criterion and the significance of the model coefficients, the optimal mean model of the samples is selected. The optimal average model of Everbright Quantitative Stock (360001) is ARMA $(3,3)$, the optimal average model of E Fund Consumption Industry (110022) is ARMA $(0,2)$, the optimal average model of Yinhua Shenzhen Securities 100 graded $(161812)$ is ARMA $(1,1)$, Yinhua-Dow Jones 88 Index A (180003) is ARMA $(3,3)$, and the optimal mean model of the China Merchants Shenzhen Stock Exchange 100 Index A (217016) is $\operatorname{ARMA}(3,3)$.

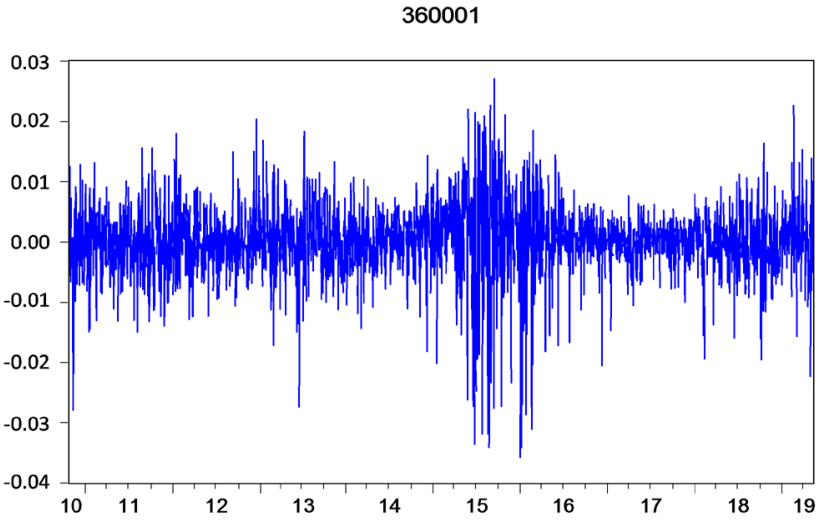

110022

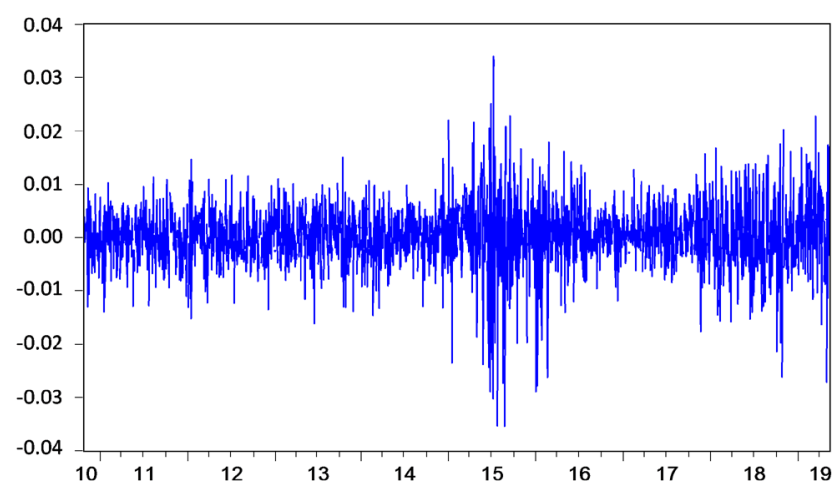


161812

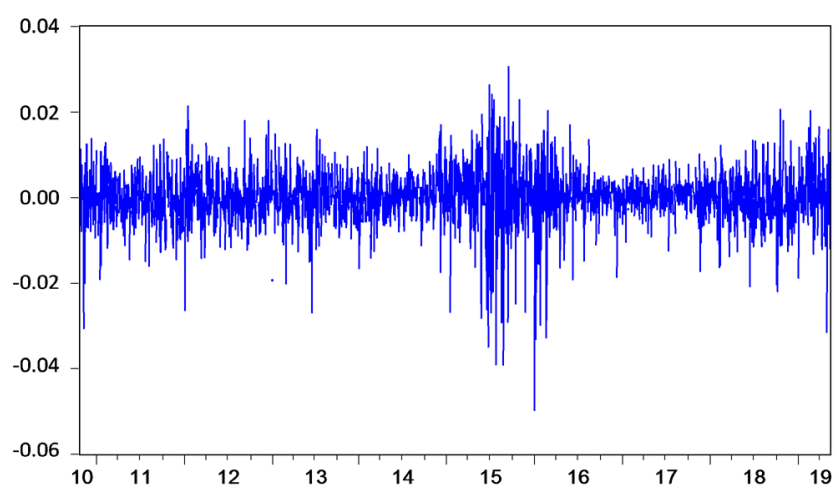

180003

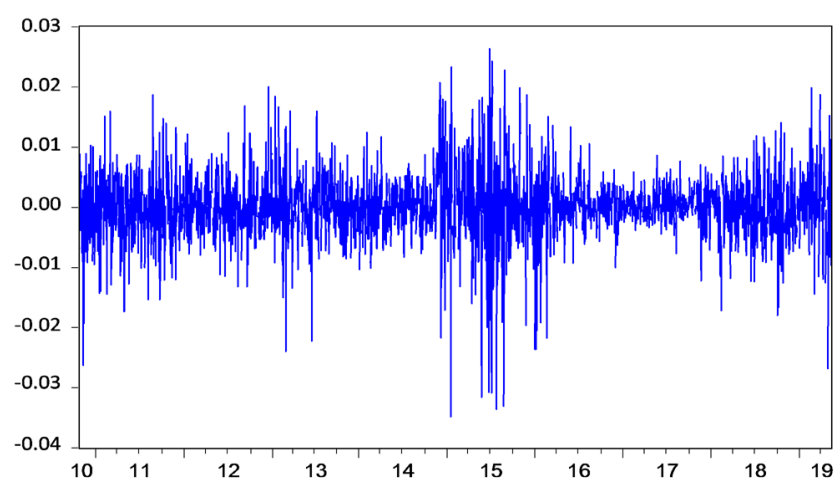

217016

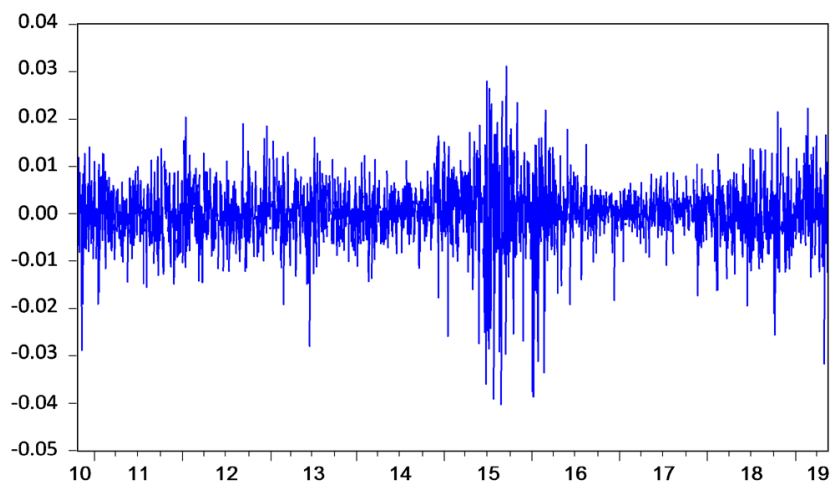

Figure 1. Daily logarithmic rate of return timing chart.

Autocorrelation test is carried out for the residual of mean model. The results show that there is no autocorrelation in the sample and the mean model is effective.

Perform a Heteroskedasticity test (Heteroskedasticity ARCH test) on the mean model, as shown in Table 3.

According to the ARCH test results, the Prob are all less than 0.05, indicating that the assumption of "there is no ARCH effect" is rejected at the significance level of 0.05 . In addition, the residual sequence is known from the residual autocorrelation graph and partial autocorrelation graph. There is a high-order truncation phenomenon, and it is believed that there is a high-order ARCH effect in the rate of return sequence. 
Table 3. ARCH test.

\begin{tabular}{cccccc}
\hline Sample & F-statistic & $\begin{array}{c}\text { Prob. } \\
\text { F(1, 2086) }\end{array}$ & ObsR-squared & $\begin{array}{c}\text { Prob. } \\
\text { Chi-Square (1) }\end{array}$ & ARCH effect \\
\hline 360001 & 117.3770 & 0.0000 & 111.2307 & 0.0000 & existence \\
110022 & 141.9637 & 0.0000 & 133.0414 & 0.0000 & existence \\
161812 & 55.96141 & 0.0000 & 54.55160 & 0.0000 & existence \\
180003 & 33.77749 & 0.0000 & 33.27137 & 0.0000 & existence \\
217016 & 111.4082 & 0.0000 & 105.8612 & 0.0000 & existence \\
\hline
\end{tabular}

\subsection{Selection of GARCH Family Models}

In determining the GARCH family model, this paper considers the t-distribution and the GED respectively, and through the AIC and SC criteria, after continuously trying the ARMA-GARCH, ARMA-GARCH-M, ARMA-TGARCH, and ARMA-EGARCH models, the final selection is made. The final models of different distributions are: for the t-distribution, the models are: ARMA $(3,3)-\mathrm{EGARCH}$ $(2,1)$, ARMA $(0,2)$-TGARCH $(1,2)$, ARMA $(1,1)$-EARCH $(1,2)$, ARMA (3, 3)-GARCH-M (1, 2), ARMA $(3,3)$-GARCH $(1,1)$; for GED, the models are: ARMA (3, 3)-GARCH $(2,1)$, ARMA $(0,2)$-TGARCH $(1,2)$, ARMA (1, 1)-GARCH-M (1, 2), ARMA (3, 3)-GARCH (1, 2). ARMA (3, 3)-GARCH (1, 1).

Use formulas (9) and (10) to calculate CVaR as shown in Table 4 below.

From the back test results, it is known that the GARCH model has a better effect of describing risks when GED is distributed. According to the principle that the smaller the DLC value is, the more accurate the model estimates the risk, the final model are ARMA $(3,3)$-GARCH $(2,1)$-GED, ARMA $(0,2)$-TGARCH $(1$, 2)-GED, ARMA $(1,1)$-EARCH $(1,2)$-t, ARMA $(3,3)$-GARCH $(1,2)$-GED, ARMA (3, 3)-GARCH $(1,1)$-GED.

The model parameters are shown in Table 5.

The results in Table 5 show that the GARCH model can well fit the data of Everbright Quantitative Stock (360001), Yinhua-Dow Jones 88 Index A (180003), and China Merchants Shenzhen Stock Exchange 100 Index A (217016). The sum of the ARCH and GARCH terms of the model are 0.9943, 0.9972, and 0.9926. Both are less than 1 and close to 1 . While satisfying the constraint conditions of the parameters, it shows that the impact of the model is durable. There is asymmetry in the volatility of the E Fund Consumption Industry (110022) and Yinhua Shenzhen Securities 100 graded (161812). The asymmetric term of E Fund's consumer industry (110022) is 0.0628 , which indicates that the impact of the negative response to the negative news is greater than the positive news, and the asymmetry increases the leverage effect. Yinhua Shenzhen Securities 100 graded (161812) is -0.0371 . The impact of good news is:

$\alpha_{1}+\alpha_{2}+\gamma=-0.0165+0.1539-0.0371=0.1003$, and the impact of bad news is: $\alpha_{1}+\alpha_{2}-\gamma=-0.0165+0.1539+0.0371=0.1745$. At this time, the impact of bad news is greater than that of good news. When investing, bad news has a greater 
impact on investors and the market than good news. However, The difference between the impact of good news and bad news is small, indicating that investors are confident in the equity funds market and believe that the development of the fund market will not happen Intense fluctuations.

LM Test is used to test the ARCH effect of the above models. The results in Table 6 show that there is no ARCH effect in the residuals of the five models, indicating that the ARCH effect is well eliminated by each model.

Table 4. CVaR back test at 95\% confidence level.

\begin{tabular}{|c|c|c|c|c|c|}
\hline & Sample & Model & Days of Failure & Failure rate & DLC \\
\hline \multirow{5}{*}{ 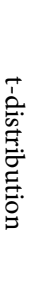 } & 360001 & ARMA $(3,3)$-EGARCH $(2,1)$ & 70 & 0.0335 & 0.0217 \\
\hline & 110022 & $\operatorname{ARMA}(0,2)$-TGARCH $(1,2)$ & 46 & 0.022 & 0.0318 \\
\hline & 161812 & ARMA $(1,1)$-EARCH $(1,2)$ & 979 & 0.4686 & 0.0086 \\
\hline & 180003 & ARMA $(3,3)$-GARCH-M $(1,2)$ & 1028 & 0.4921 & 0.0094 \\
\hline & 217016 & $\operatorname{ARMA}(3,3)$-GARCH $(1,1)$ & 974 & 0.4663 & 0.0120 \\
\hline \multirow{5}{*}{ 界 } & 360001 & $\operatorname{ARMA}(3,3)$-GARCH $(2,1)$ & 117 & 0.056 & 0.0028 \\
\hline & 110022 & $\operatorname{ARMA}(0,2)$-TGARCH $(1,2)$ & 78 & 0.0374 & 0.0105 \\
\hline & 161812 & ARMA $(1,1)$-GARCH-M $(1,2)$ & 979 & 0.4686 & 0.0120 \\
\hline & 180003 & ARMA $(3,3)-$ GARCH $(1,2)$ & 132 & 0.0632 & 0.0019 \\
\hline & 217016 & ARMA $(3,3)-G A R C H(1,1)$ & 974 & 0.4663 & 0.0119 \\
\hline
\end{tabular}

Table 5. ARMA-GARCH family model corresponding parameters.

\begin{tabular}{|c|c|c|c|c|c|}
\hline Sample & 360001 & 110022 & 161812 & 180003 & 217016 \\
\hline $\begin{array}{c}\text { Mean-variance } \\
\text { equation }\end{array}$ & $\begin{array}{c}\operatorname{ARMA}(3,3)- \\
\text { GARCH }(2,1)-\text { GED }\end{array}$ & $\begin{array}{c}\text { ARMA }(0,2)- \\
\text { TGARCH }(1,2)-\text { GED }\end{array}$ & $\begin{array}{l}\operatorname{ARMA}(1,1)- \\
\text { EARCH }(1,2)-\mathrm{t}\end{array}$ & $\begin{array}{c}\operatorname{ARMA}(3,3)- \\
\text { GARCH }(1,2)-\text { GED }\end{array}$ & $\begin{array}{c}\operatorname{ARMA}(3,3)- \\
\text { GARCH }(1,1)-\text { GED }\end{array}$ \\
\hline$\phi_{1}$ & -0.6524 & - & -0.8660 & -0.6803 & -0.6731 \\
\hline$\phi_{2}$ & -0.8300 & - & - & -0.8395 & -0.8023 \\
\hline$\phi_{3}$ & -0.8584 & - & - & -0.8036 & -0.8388 \\
\hline$\theta_{1}$ & 0.6751 & 0.4481 & 0.9149 & 0.6771 & 0.6962 \\
\hline$\theta_{2}$ & 0.7535 & -0.0930 & - & 0.7893 & 0.7654 \\
\hline$\theta_{3}$ & 0.8758 & - & - & 0.8005 & 0.8848 \\
\hline$\omega$ & $1.14 \mathrm{E}-06$ & $7.19 \mathrm{E}-06$ & -0.2436 & $8.66 \mathrm{E}-14$ & $2.16 \mathrm{E}-11$ \\
\hline$\alpha_{1}$ & 0.0332 & -0.0317 & -0.0165 & -0.0266 & 0.0529 \\
\hline$\alpha_{2}$ & - & 0.0903 & 0.1539 & 0.0957 & - \\
\hline$\beta_{1}$ & 1.2951 & 0.8747 & 0.9859 & 0.9281 & 0.9397 \\
\hline$\beta_{2}$ & -0.3340 & - & - & - & - \\
\hline$\gamma$ & - & 0.0628 & -0.0371 & - & - \\
\hline
\end{tabular}


Table 6. ARCH-LM test.

\begin{tabular}{cccccc}
\hline Sample & F-statistic & $\begin{array}{c}\text { Prob. } \\
\text { F }(1,2086)\end{array}$ & $\begin{array}{c}\text { Obs }{ }^{*} \\
\text { R-squared }\end{array}$ & $\begin{array}{c}\text { Prob. Chi-Square } \\
(1)\end{array}$ & ARCH effect \\
\hline 360001 & 0.3270 & 0.5675 & 0.3272 & 0.5673 & Non-existent \\
110022 & 1.3938 & 0.2379 & 1.3942 & 0.2377 & Non-existent \\
161812 & 0.8058 & 0.3695 & 0.8062 & 0.3692 & Non-existent \\
180003 & 0.5391 & 0.4629 & 0.5395 & 0.4627 & Non-existent \\
217016 & 1.3975 & 0.2373 & 1.3979 & 0.2371 & Non-existent \\
\hline
\end{tabular}

\subsection{Calculation of Risk and Performance Based on GARCH Family Models}

In the case of $95 \%$ confidence level, quantile and conditional standard deviation of the model are calculated by Eviews, and CVaR value is calculated by MATLAB according to Formula (9) and (10) as shown in Table 7.

As can be seen from Table 7, the risk value ranking of E Fund's consumer industry (110022) is the largest. The risk value rankings of Everbright Quantitative Stock (360001), Yinhua-Dow Jones 88 Index A (180003), China Merchants Shenzhen Stock Exchange 100 Index A (217016), and Yinhua Shenzhen Securities 100 graded (161812) is 2nd, 3rd, 4th and 5th respectively. The larger the CVaR value, the higher the ranking, and the higher the risk. Therefore, the CVaR value of the five samples can determine that the risk of E Fund Consumption Industry (110022) is the largest, and the risk of Yinhua Shenzhen Securities 100 graded 9161812) is the smallest.

Use Formulas (11) and (13) to calculate PM and CVaR-RAROC, the results are as in Table 8.

It can be seen from Table 8 that PM and CVaR-RAROC are the same in the top three performance rankings, and the last two are different. According to the comprehensive performance and risk ranking: under the PM and CVaR-RAROC performance evaluation rules, the two performance ranking and risk ranking of E Fund Consumption Industry (110022), Everbright Quantitative Stock (360001) and Yinhua-Dow Jones 88 Index A (180003) are the same, ranking 1st, 2th and 3th respectively; the performance ranking of Yinhua Shenzhen Securities 100 graded (161812) shows that: PM method is the 4th, CVaR-RAROC is the 5th, and risk ranking is the 5th; The performance ranking of Yinhua Shenzhen Stock Exchange 100 shows that PM method is the fourth, CVaR-RAROC method is the fifth, and risk ranking is the fifth; the performance ranking of China Merchants Shenzhen Stock Exchange 100 Index A (217016) shows that CVaR-RAROC method is the 4th, PM method is the 5th, and risk ranking is the 4th. The comparison found that the final ranking of the results measured by CVaR-RAROC is consistent with the risk ranking, while the performance ranking of the PM method and the risk ranking have little difference, so the CVaR-RAROC method is used to measure the fund performance. The top performance ranking is also the 
Table 7. CVaR risk ranking at 95\% confidence level.

\begin{tabular}{cccccc}
\hline Sample & CVaR's maximum & CVaR's minimum & CVaR's mean & CVaR's Std.DV & Ranking \\
\hline 360001 & 0.0962 & 0.0122 & 0.0284 & 0.0161 & 2 \\
110022 & 0.1027 & 0.0111 & 0.0295 & 0.0172 & 1 \\
161812 & $5.22 \mathrm{E}-05$ & $2.23 \mathrm{E}-05$ & $3.22 \mathrm{E}-05$ & $5.67906 \mathrm{E}-06$ & 5 \\
180003 & 0.0850 & 0.0086 & 0.0236 & 0.0116 & 3 \\
217016 & $3.39 \mathrm{E}-04$ & $4.24 \mathrm{E}-05$ & $1.00 \mathrm{E}-04$ & $4.83002 \mathrm{E}-05$ & 4 \\
\hline
\end{tabular}

Table 8. PM, CVaR-RAROC legal evaluation ranking.

\begin{tabular}{ccccc}
\hline Sample & PM & Ranking & CVaR-RAROC & Ranking \\
\hline 360001 & -1.29067 & 2 & 0.001269 & 2 \\
110022 & -0.10816 & 1 & 0.015962 & 1 \\
161812 & -9.25943 & 4 & -0.04395 & 5 \\
180003 & -1.55406 & 3 & 0.001086 & 3 \\
217016 & $-3.65 \mathrm{E}+02$ & 5 & $1.46 \mathrm{E}-01$ & 4 \\
\hline
\end{tabular}

top risk ranking, and the bottom performance ranking is also the bottom risk ranking. Therefore, the greater the risk of the equity funds, the greater the return, the better the performance. Among these 5 funds, investors who can accept high risks can choose E Fund Consumption Industry (110022) to obtain greater returns, and more conservative investors can choose funds that are more stable like the Y Yinhua-Dow Jones 88 Index A (180003).

Comparing risk ranking and performance ranking, it is found that the results of risk ranking and sharp ratio method are consistent. The ranking of comprehensive risk and performance found that the better the performance of equity funds, the higher the returns, the greater the risks. Equity funds have the characteristics of investment products "high return, high risk".

\section{Conclusions}

In this paper, the ARMA-GARCH model of the t-distribution and GED is established. Through CVaR back testing, it is found that under the GED, the model has a better effect of measuring risk. Under the 95\% confidence level, the risk and performance indicators CVaR, PM, and CVaR-RAROC are calculated. The results show that the performance rankings of the Sharpe ratio method and the RAROC method are different. The performance ranking and risk ranking calculated by the CVaR-RAROC method Consistent. Comprehensive risk and performance ranking can be found that the higher the return, the greater the risk, there is a corresponding relationship of "high risk, high return" for equity funds.

To sum up, investment products have risks as well as returns. If investors have low financial literacy, they cannot fully collect and accurately identify the risks of 
related financial products, and thus make poor financial decisions, which will harm the harmony of investors and society. The research of this paper can help investors understand the risk and performance of equity funds more comprehensively, so as to make accurate investment decisions, and provide decision-making basis and reference for financial institutions and regulatory departments.

\section{Fund Project}

National Natural Science Foundation of China (61703117); Guangxi Young and Middle-aged Teacher's Basic Ability Improvement Project (2018ky0261).

\section{Conflicts of Interest}

The authors declare no conflicts of interest regarding the publication of this paper.

\section{References}

[1] Song, G.H., Tian, L.M. and Wu, X. (2015) SHIBOR Risk Measurement Based on VaR and CVaR Models of GARCH Family. Finance and Accounting Monthly, No. 33, 41-45.

[2] Wei, Z.Y., Yu, D.Y. and Li, S.P. (2018) Research and Application of Realized GARCH-GED Model. Journal of Chongqing University of Technology (Natural Science), 32, 273-278.

[3] Zhao, Z.Q. and Li, X.Z. (2006) Empirical Research on Risk Comparison of Open-End Funds. Contemporary Economic Research, No. 4, 51-55.

[4] Huang, C.Z. and Cao, Q. (2017) Risk Measurement on Open-end Fund Based on GARCH-VaR Model. Statistics \& Decision, No. 1, 152-155.

[5] Qi, Y. and Sun, X.M. (2016) Funds Performance Evaluation Based on the Investment Strategies. Management Review, 28, 155-165.

[6] Liu, J.S. (2007) Comparative Studies of VaR and CVaR Based on the Extreme Value Theory. The Journal of Quantitative \& Technical Economics, No. 3, 125-133.

[7] Zhu, F.Y., Zhou, Y. and Chen, Y. (2018) Empirical Analysis on Risk and Performance of Internet Finance Products. Journal of Shanghai Lixin University of Accounting and Finance, No. 6, 60-69.

[8] Tang, Z.P. and Peng, W. (2010) Chinese Open-End Funds Evaluation of RAROC Based on CVaR. Systems Engineering-Theory \& Practice, 30, 1403-1413.

[9] Huang, J.B., Li, Z.F. and Ding, J. (2018) Research on Fund Performance Measure with CVaR. Management Review, 30, 20-32.

[10] Box, G.E.P. and Jenkins, G.M. (1976) Time Series Analysis-Forecasting and Control. Holden-Day, Revised Edition, San Francisco, CA, 575 p.

[11] Bollerslev, T. (1985) Generalized Autoregressive Conditional Heteroscedasticity. Journal of Econometrics, 18, 931.

[12] Engle, R.F., Lilien, D.M. and Robins, R.P. (1987) Estimating Time-Varying Premia in the Term Structure: The ARCH-M Model. Econometrics, 55, 391-407. https://doi.org/10.2307/1913242

[13] Zakoian, J.M. (1994) Threshold Heteroscedastic Models. Journal of Economic Dynamics and Control, 18, 931-955. https://doi.org/10.1016/0165-1889(94)90039-6 
[14] Glosten, L., Jagannathan, R. and Runkle, D. (1993) On the Relation between the Expected Value and the Volatility of Nominal Excess Retune on Stocks. Journal of Financial, 48, 1779-1801. https://doi.org/10.1111/j.1540-6261.1993.tb05128.x

[15] Nelson, D.B. (1991) Conditional Heteroskedasticity in Asset Returns: A New Approach. Econometica, 59, 347-370. https://doi.org/10.2307/2938260

[16] Rockafeller, T. and Uryasev, S. (2000) Optimization of Conditional Value-at-Risk. Journal of Risk, 2, 21-24. https://doi.org/10.21314/JOR.2000.038 